\title{
Communication
}

\section{Application of 3D DIC-Assisted Residual Stress Measurements for Friction Stir Welding Weld from Ultrafine-Grained Aluminum}

\section{TOMASZ BRYNK, MARTA ORłOWSKA, and MAłGORZATA LEWANDOWSKA}

The present study describes a novel approach applying 3D digital image correlation to a hole drilling method to measure residual stresses. Measurements were performed on a friction stir-welded joint made of ultrafine-grained aluminum. The results show that severe plastic deformation did not significantly change the residual stresses, while in the weld's stir zone they increased to 100 to $200 \mathrm{MPa}$. The obtained results demonstrate the reliability of the applied residual stress measurement method.

https://doi.org/10.1007/s11661-020-06069-5

(C) The Author(s) 2020

Knowledge of the residual stresses is very important in many industrial applications. One of the most prominent examples are welds, because during welding a material is subjected to a complex thermal treatment that results in high residual stresses. Frequently, residual stresses in welds are measured using the hole-drilling method ${ }^{[1]}$ In this work, we describe a modification of this technique based on deformation measurements close to the holes. Conventionally, such measurements are carried out using strain gauge rosettes; here, 3D digital image correlation (DIC) is used. Such a modification allows not only delivering an increased number of measurement points, but also reduction of the distance between the holes.

A DIC-assisted method was applied to a weld made using friction stir welding (FSW), ${ }^{[2]}$ which is one of the modern welding techniques that takes place in the solid

TOMASZ BRYNK is with the Faculty of Materials Science and Engineering, Warsaw University of Technology, Wołoska 141, 02-507 Warsaw, Poland and also with the SCK CEN, Boeretang 200, 2400 Mol, Belgium. MARTA ORŁOWSKA and MAŁGORZATA LEWANDOWSKA are with the Faculty of Materials Science and Engineering, Warsaw University of Technology.

Manuscript submitted August 13, 2020 and accepted October 14, 2020.

Article published online November 17, 2020 state. It can therefore be used for joining heat-sensitive materials, such as those that are ultrafine grained (UFG). UFG materials feature superior strength because of their reduced grain size, and thereby elevated surface area of grain boundaries, and increased density of dislocations. They are commonly produced using severe plastic deformation (SPD $)^{[3]}$ methods. One such method that makes it possible to produce plates suitable for FSW is incremental equal channel angular pressing (I-ECAP) ${ }^{[4]}$ The weld investigated was selected in such a way that the influence of both the SPD processing and the welding method on the residual stresses could be investigated.

As a base material for welding, commercially pure aluminum 1050 (99.50 wt pct) was chosen in the form of plates with dimensions of $3 \times 62 \times 100 \mathrm{~mm}^{3}$. Material annealed at $450{ }^{\circ} \mathrm{C}$ for 2 hours has grain size at a level of about $12.9 \mu \mathrm{m}$ and a fraction of high-angle grain boundaries (HAGBs) reaching 81.7 pct. After eight passes of I-ECAP with route $\mathrm{C}$, the microstructure underwent a reduction in grain size to about $1 \mu \mathrm{m}$, resulting in a fraction of HAGBs of 53.2 pct (for details on the processing procedure and microstructure features, see $\left.{ }^{[5]}\right)$. A TEM micrograph of this sample is presented in Figure 1(a). Similar welding was performed using FSW with a tool having a shoulder diameter of 12 $\mathrm{mm}$. A tapered, threaded pin with a length of $2.85 \mathrm{~mm}$, diameter at the shoulder of $5 \mathrm{~mm}$ and diameter at the tip of $3.5 \mathrm{~mm}$ was used. A rotational speed of $800 \mathrm{rpm}$ and linear speed of $400 \mathrm{~mm} / \mathrm{min}$ were applied. The angle of inclination of the tool was $1.5 \mathrm{deg}$. The microstructure of the stir zone (SZ), presented in Figure 1(b), features an average grain size of $3.1 \mu \mathrm{m}$ and a fraction of HAGBs of 75 pct. The microstructure in the SZ is a result of dynamic recrystallization. Closer to the SZ, not only the grain size, but also the fraction of HAGBs, dislocation density and microtexture components changed. An EBSD orientation map of a cross section of the weld is shown in Figure 2. Both processes, i.e., I-ECAP and FSW, introduced a shear texture. Nevertheless, they differed in their major components, as seen from the $\{111\}$ pole figures. For the base material, which is after I-ECAP, the texture consists mainly of simple shear components A $\{111\}\langle 110\rangle$ and $\mathrm{C}\{001\}\langle 110\rangle$, as described in Reference 6. For the stir zone, the major shear texture component is $\mathrm{A}^{*}\{111\}\langle 112\rangle$. A comprehensive study of the microstructure and mechanical properties of welds was described in our previous paper. ${ }^{[5]}$

The mapping of microhardness as measured on the surface of the weld is shown in Figure 3. The average microhardness of the annealed sample was 25 HV0.2. Processing using the I-ECAP method caused an increase to the value of $55 \mathrm{HV} 0.2$. This was caused by the grain boundary and dislocation strengthening mechanisms, as their surface area was significantly elevated after the SPD processing. In the SZ, a significant drop can be 


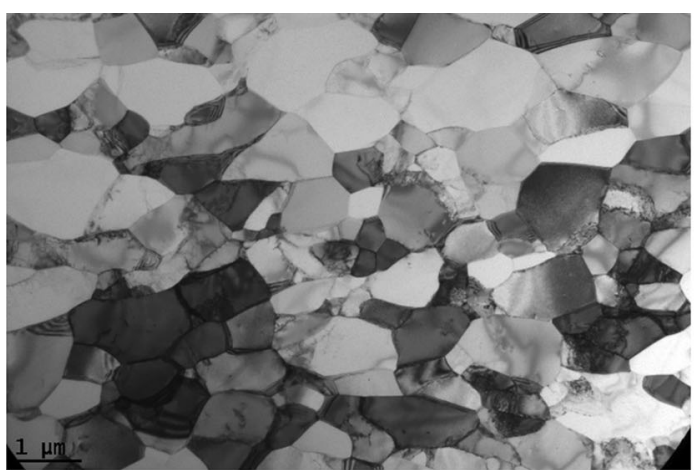

(a)

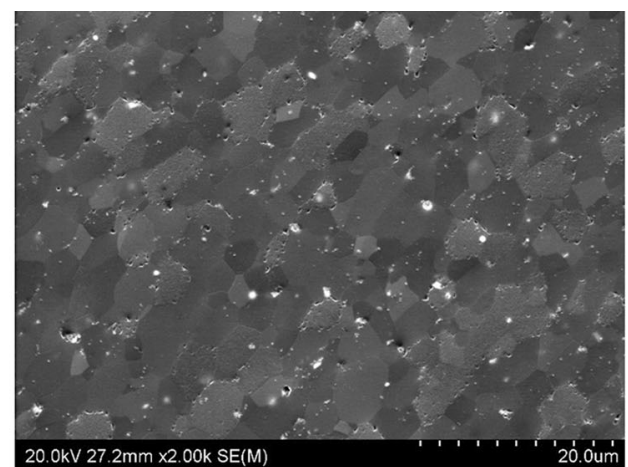

(b)

Fig. 1-Microstructure of $(a)$ base material and $(b)$ stir zone of the weld.

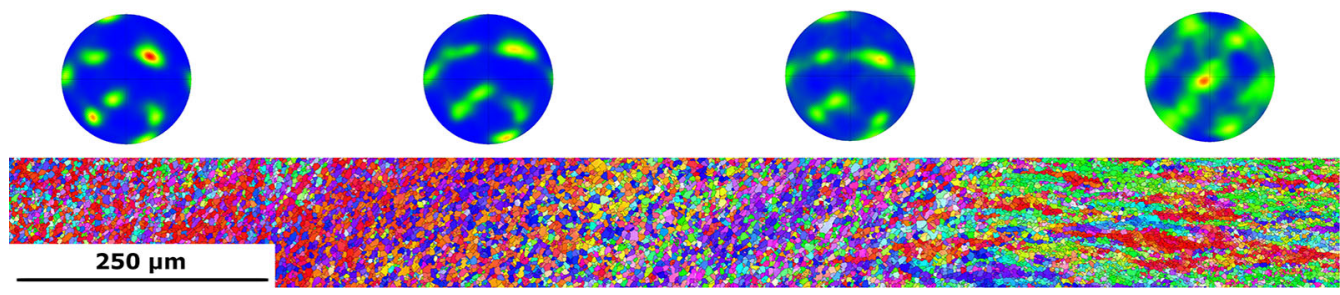

Fig. 2-OIM of the weld from the base material (on the right) to the stir zone (on the left) together with $\{111\}$ pole figures from the corresponding weld areas.

noticed. The average value of microhardness is 31 HV0.2. Between the SZ and base material, a transition zone can be noticed, where the microhardness varies from 32 to $50 \mathrm{HV} 0.2$. This area covers the thermomechanically affected zone and the heat-affected zone. Such a drop in microhardness is typical for work-hardened non-heat-treatable alloys and is caused by dynamic recrystallization, which results in increased grain size in the stir zone compared with the base material. ${ }^{[7]}$

An inverse method procedure was applied to determine the residual stress distribution in the investigated material by selecting an optimized set the of equation coefficients describing the displacement field near the drilled holes. Due to a lack of direct equations for the blind hole case, corrections to the equations for the through-the-hole case were applied based on the results of finite element method simulations. The methodology of correction determination is presented in Reference 8 for one particular case of the blind hole geometry (hole depth-to-hole diameter ratio $h / d=1.2$ and selected normalized distances from the hole center, $\left.r / r_{0}\right)$. In Reference 9 this methodology has been extended to a wide range of blind hole geometry cases. The arrays of correction coefficients were determined for discrete values of $h / d$ and $r / r_{0}$ allowing to interpolate in-between values and making it convenient to use in the inverse method-based calculations of residual stress components.

The testing set-up designed for the DIC-assisted measurements, which needed no displacement of the cameras during the time of drilling, was built of generally available components. The drilling speed was $\sim 10,000 \mathrm{rpm}$, which is lower than that in commercial systems designed for measurements with strain gauges. Details on the measurement procedure and the results for 316LVM steel produced by SPD are presented in Reference 9. Here, the developed methodology was applied to a material with a lower hardness and expected lower residual stresses level. Therefore, the influence of the drilling process also had to be taken into consideration.

Holes were drilled in two steps to 0.25 and $0.5 \mathrm{~mm}$ with a $0.5-\mathrm{mm}$ mill. The effective hole diameter measured after testing was $0.58 \mathrm{~mm}$. In addition to the reference image recorded before drilling, three images for each drilling step were recorded and processed using ViC 3D software. Displacement field data from the area, limited to a radius of four times larger than the effective hole radius $\left(r_{\text {cut }}=1.16 \mathrm{~mm}\right)$, were taken as input data for the inverse method scripts, and the average results of three calculations of $\sigma_{x x}, \sigma_{y y}$ and $\sigma_{x y}$ were delivered.

The aim of calculation scripts was to optimize, in the least square difference sense, sets of parameters (residual stress components $\sigma_{x x}, \sigma_{y y} \sigma_{x y}$, rigid body movements: $T_{x}, T_{y}, R$ and hole position $x_{0}$ and $\left.y_{0}\right)$ in equations on horizontal and vertical displacement field components near the drilled holes for all analyzed data points:

$$
\begin{aligned}
u_{x i}= & f\left(E, v, \sigma_{x x}, \sigma_{y y}, \sigma_{x y}, x_{i}, y_{i}, A^{\prime}, B^{\prime}, x_{0}, y_{0}, T_{x}, T_{y}, R\right) \\
& -u_{x i} \mathrm{DIC}
\end{aligned}
$$


$u_{y i}=f\left(\sigma_{x x}, \sigma_{y y}, \sigma_{x y}, x_{i}, y_{i}, C^{\prime}, x_{0}, y_{0}, T_{x}, T_{y}, R\right)-u_{y i}$ DIC

where $i$ indicates the data point index; $A^{\prime}, B^{\prime}$ and $C^{\prime}$ are the correction parameters for the blind hole dependent on the hole depth and distance from the hole center $\left(\operatorname{see}^{[9]}\right) ; u_{x i}$ DIC and $u_{y i}$ DIC are the displacement field components from DIC.

A preliminary examination of the annealed aluminum specimen showed that the drilling process had introduced a deformation resulting in 35 to $75 \mathrm{MPa}$ stress in the $x$ and $y$ directions and a shear stress near zero (Figure 4). Therefore, the results presented for the weld specimens should be treated mostly as quantitative, and the changes in the presented values are expected to give approximate qualitative information, based on the assumption that in all drilling cases the amount of stress introduced from the drilling was the same.

A diagram of the hole positioning in the 3-mm-thick, $15-\mathrm{mm}$-wide and 60 -mm-long plate is presented in Figure 5. Selected distancing made it possible to determine profiles of the residual stress component distribution, with distances of 1 and $2 \mathrm{~mm}$ at 0 to $10 \mathrm{~mm}$ and 10 to $14 \mathrm{~mm}$ from the weld center, respectively.

Exemplary displacement field maps presenting the results of the DIC measurements for a selected region near the hole together with the results of the analytical equations corrected for the blind hole case are presented in Figure 6. Only those data points for which the error defined in the DIC software was below a specified limit were taken into account in the residual stress calculations. Therefore, white areas are visible on the maps in

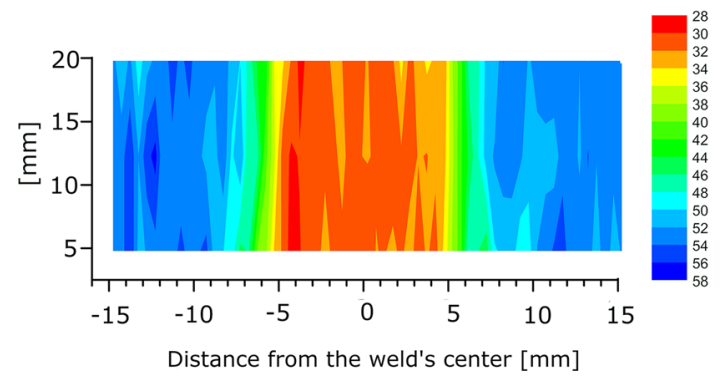

Fig. 3-Microhardness distribution on the weld surface. those regions where the speckle pattern was destroyed during the drilling process. More severe destruction of the speckle pattern was avoided by using a strong air flow during the drilling. The difference between the DIC measurements in horizontal and vertical directions and the model with optimized parameter results is noticeable only in those areas very close to the hole. For the rest of the analyzed area, the value is close to zero, which shows the validity of the applied calculation procedure.

The results of the measurements are shown in Figure 7. The residual stress components for the same locations in the weld delivered from the 0.25 and 0.5 depth holes are in close accordance. The base material, which was processed by I-ECAP, displays values of residual stresses similar to those of the annealed sample (Figure 4), even the microhardness value was doubled after plastic deformation. The SPD processing influences the value of residual stresses; however, this phenomenon has been sparingly described in the literature. It can be stated that the influence is the most pronounced at the lower values of deformation strain, and it decreases with the further deformation due to microstructure homogenization. The AA2017 processing by ECAP led to an increase in residual stresses after one pass, while after the third pass the value of the residual stresses decreased, which was attributed to dynamic recovery phenomena occurring during further passes (up to 6). ${ }^{[10]}$ Also, the residual stresses decreased with subsequent passes of parallel tubular channel angular pressing of A16061. ${ }^{[11]}$ As an explanation of this phenomenon, the authors suggest that it can be the result of decreasing gradients of axial and tangential stresses along the thickness of the tube, which

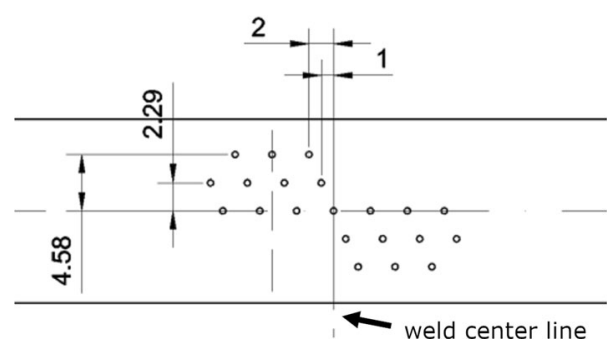

Fig. 5-Diagram of hole positioning in the welded sample.
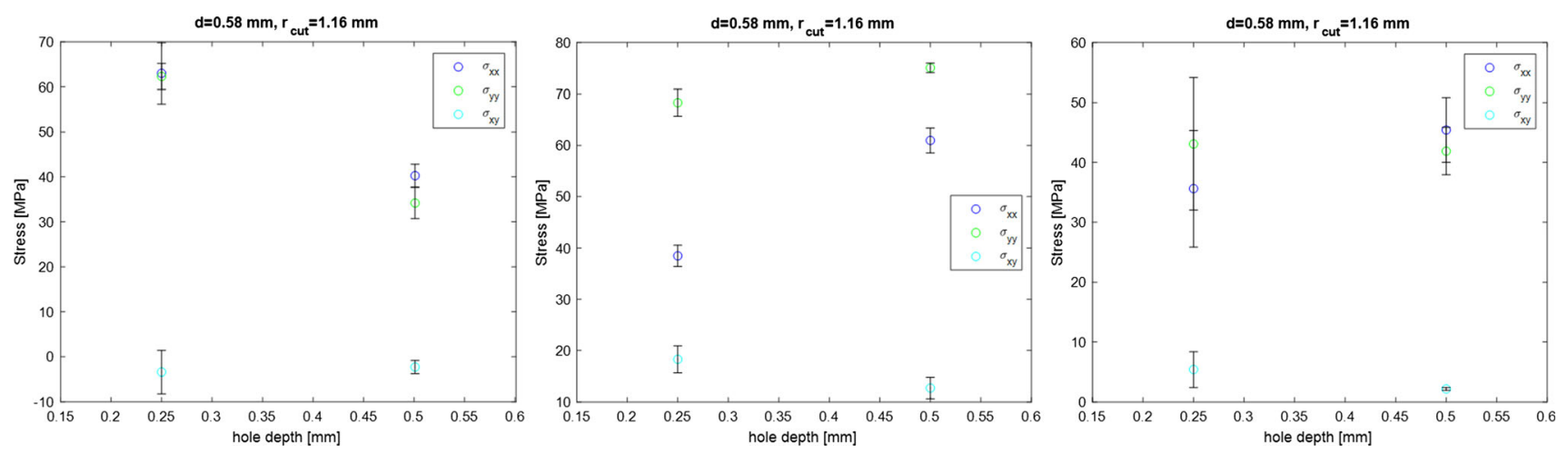

Fig. 4-Impact of drilling on residual stress measurements in an annealed aluminum specimen for three different holes. 


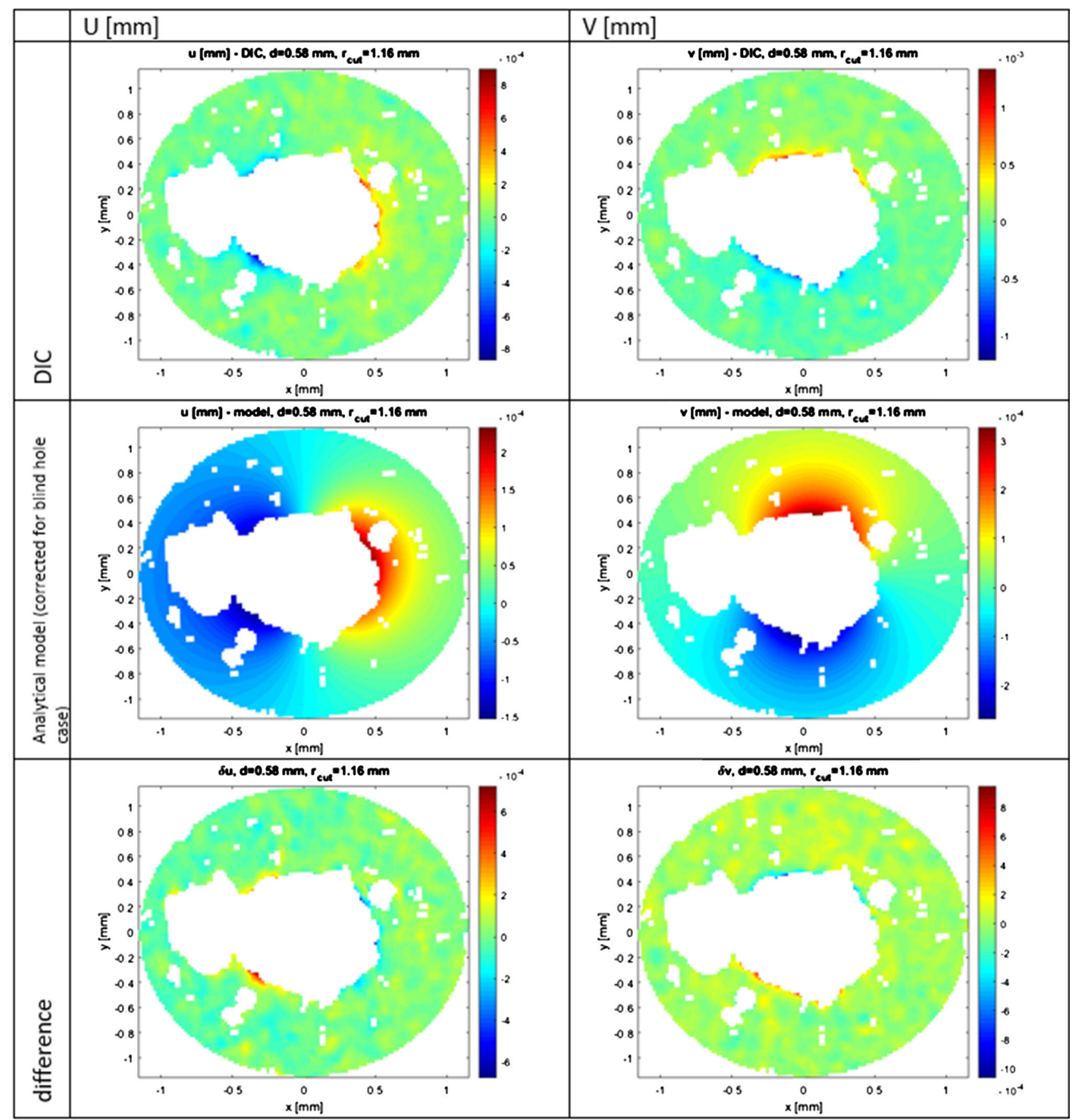

Fig. 6-Sample displacement field maps from DIC measurements and analytical model after parameter optimization and difference between DIC measurements and the model. I-ECAP specimen, weld center, $\sigma_{x x}=79 \mathrm{MPa}, \sigma_{y y}=108, \sigma_{x y}=4 \mathrm{MPa}$.

subsequently reduced the value of the residual stress. The results of four passes were about half of the results of the residual stresses obtained after one pass.

From the available papers concerning the residual stresses in UFG materials after SPD processing, it can be concluded that initial deformation, usually one pass $(\varepsilon \sim 1)$, results in an increase in residual stresses, whereas further deformation causes their reduction. Such a correlation was found in Reference 12 where for commercial pure copper with subsequent passes of constrained groove pressing (CGP) the grain size, crystallite size, lattice strain and residual stresses all decreased while the dislocation density increased. It was shown that the residual stresses decreased with an increasing number of CGP, mainly because of increasing homogeneity. This could be also the reason for the comparable values of residual stresses in the present study for the annealed sample $(\varepsilon=0)$ and after IECAP. Eight passes resulted in a high value of accumulated strain, $\varepsilon=9.2$, which caused a significant grain 


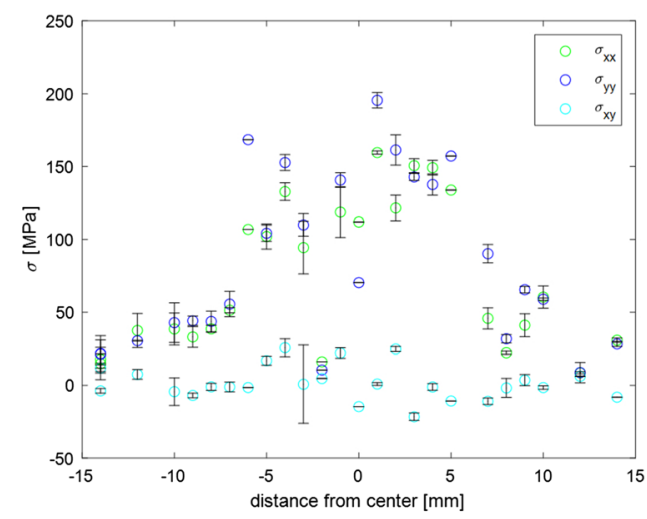

(a)

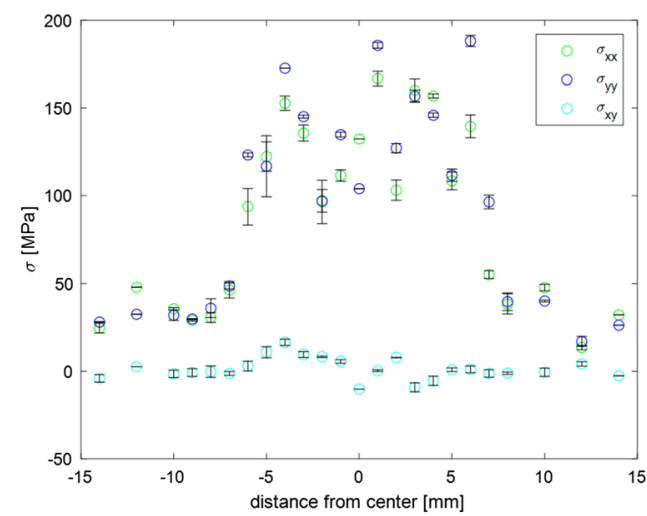

(b)

Fig. 7-Specimen IECAP, drilling depth (a) $0.25 \mathrm{~mm}$, (b) $0.5 \mathrm{~mm}$; advancing side of the weld on the left.

refinement and resulted in the formation of a large number of grain boundaries. The increased number of grain boundaries could also be responsible for the decrease in the residual stresses because of a spread of relaxation. Moreover, one of the advantages of the IECAP process is that frictional forces are significantly reduced because of the deformation being applied in an incremental manner. This reduces compressive stresses at the sample surface.

Much more pronounced changes in values of residual stresses are observed in weld's center. The weld exhibits a stress distribution that is close to symmetric in reference to its center, oscillating from 100 to 200 MPa for $\sigma_{x x}$ and $\sigma_{y y}$ in a stir zone. In case of shear stresses, the values are much lower; however, a small increase can be noticed in the advancing side of the weld. As a result of the process in the weld's center, a peak in the tensile residual stresses is found. Similar results, with lower balancing compressive residual stresses present outside of the tensile region, were shown in Reference 13 with residual stresses of 80 to $170 \mathrm{MPa}$ in the weld zone for AA7010, depending on the FSW parameters. Results of 60 to $140 \mathrm{MPa}$ were obtained for both numerical and experimental investigations of FSW welds from Al alloys in Reference 14. Moreover, travel speed was shown to be the most important factor in establishing the maximum longitudinal residual stress compared with rotation speed. Similar values of the tensile residual stresses in a stir zone for 3-mm-thick plates of FSW AA6061 were obtained in Reference 15 with higher HAZ values on the advancing side, and in Reference 16 with maximum tensile residual stress in the stir zone, depending on the modified FSW process parameters, were estimated at the value of 132 to 173 $\mathrm{MPa}$. In the present study the results between the advancing and retreating side were the most pronounced in case of shear stress, which was higher on the advancing side of the stir zone for both drilling depths. For stresses in the $x$ and $y$ directions the results are more diverse and there is no clear dominance of either side.

The residual stresses on the FSW welds of different $\mathrm{Al}$ alloys were also investigated in Reference 17 using the hole-drilling method. The results showed that residual stresses are negative at the surface of the examined zone and increase with depth, reaching values of about 100 to $150 \mathrm{MPa}$ at a depth of about 0.5 to $1.0 \mathrm{~mm}$. The results obtained in the present study are in very good accordance with the available data results for FSW welds, measured by various methods. More pronounced differences of the results of residual stress values for $\mathrm{Al}$ alloys after FSW are achieved only for modifications of the sample, e.g., some additions, such as nanoparticles. ${ }^{[18]}$ Therefore, it can be concluded that the applied method is feasible and reliable for measuring residual stresses in FSW joints.

The present work shows that the proposed procedure of residual stress measurements near drilled holes utilizing 3D DIC displacement fields can be successfully applied to aluminum welds made by friction stir welding. A close to symmetric distribution of residual stress components was observed. I-ECAP processing ( 8 passes) had only a minor impact on the value of the residual stresses compared with the annealed sample. In contrast, the FSW process introduced tensile residual stresses ranging from 100 to $200 \mathrm{MPa}$ in the stir zone.

This work was supported by The National Science Center (Poland) under Contract 2016/21/D/ST8/02019. The authors thank L. Olejnik from Warsaw University of Technology for performing the I-ECAP process and A. Hütter and N. Enzinger from Graz University of Technology for conducting the FSW.

\section{OPEN ACCESS}

This article is licensed under a Creative Commons Attribution 4.0 International License, which permits use, sharing, adaptation, distribution and reproduction in any medium or format, as long as you give appropriate credit to the original author(s) and the source, provide a link to the Creative Commons licence, and 
indicate if changes were made. The images or other third party material in this article are included in the article's Creative Commons licence, unless indicated otherwise in a credit line to the material. If material is not included in the article's Creative Commons licence and your intended use is not permitted by statutory regulation or exceeds the permitted use, you will need to obtain permission directly from the copyright holder. To view a copy of this licence, visit http:// creativecommons.org/licenses/by/4.0/.

\section{REFERENCES}

1. J. Guo, H. Fu, B. Pan, and R. Kang: Chin. J. Aeronaut., 2020, https://doi.org/10.1016/j.cja.2019.10.010.

2. R.S. Mishra and Z.Y. Ma: Mater. Sci. Eng. R Rep., 2005, vol. 50, pp. 1-78, https://doi.org/10.1016/j.mser.2005.07.001.

3. R.Z. Valiev, Y. Estrin, Z. Horita, T.G. Langdon, M.J. Zehetbauer, and Y. Zhu: JOM, 2006, vol. 58, pp. 33-39, https://doi.org/ 10.1007/s11837-016-1820-6.

4. L. Olejnik, A. Rosochowski, and M. Richert: Mater. Sci. Forum, 2008, vols. 584-586, pp. 108-13.

5. M. Orlowska, T. Brynk, A. Huetter, J. Goliński, N. Enzinger, L. Olejnik et al.: Mater. Sci. Eng. A, 2020, vol. 777, p. 139076, https:/ doi.org/10.1016/j.msea.2020.139076.

6. F.C. Liu and T.W. Nelson: Mater. Des., 2017, vol. 115, pp. 467-78, https://doi.org/10.1016/j.matdes.2016.11.066.

7. P.L. Threadgill, A.J. Leonard, H.R. Shercliff, and P.J. Withers: Int. Mat. Rev., 2009, vol. 54, pp. 49-93, https://doi.org/10.1179/ $174328009 \times 411136$.
8. A. Makino and D. Nelson: Exp. Mech., 1994, vol. 34, pp. 66-78.

9. T. Brynk, A.T. Krawczyńska, D. Setman, and Z. Pakieła: Arch. Civ. Mech. Eng., 2020, vol. 4, pp. 1-12, https://doi.org/10.1007/ s43452-020-00068-4.

10. L. Romero-Resendiz, C. Reyes-Ruiz, J.M. Cabrera, C. Braham, and G. Gonzalez: Mater. Charact., 2019, vol. 152, pp. 44-57.

11. H. Sanati, F. Reshadi, G. Faraji, N. Soltani, and E. Zalnezhad: Proc. Inst. Mech. Eng. B, 2014, https://doi.org/10.1177/ 0954405414534432.

12. F. Nazari, M. Honarpisheh, and H. Zhao: Micron, 2020, vol. 132, p. 102843, https://doi.org/10.1016/j.micron.2020.102843.

13. T. Sun, M.J. Roy, D. Strong, P.J. Withers, and P.B. Prangnell: $J$. Mater. Process. Tech., 2017, vol. 242, pp. 92-100, https://doi.org/ 10.1016/j.jmatprotec.2016.11.015.

14. L. Buglioni, L.N. Tufaro, and H.G. Svoboda: ProcediaMater. Sci., 2015, vol. 9, pp. 87-96, https://doi.org/10.1016/ j.mspro.2015.04.011.

15. I. Alinaghian, S. Amini, and M. Honarpisheh: J. Strain Anal., 2018, https://doi.org/10.1177/0309324718789768

16. I. Alinaghian and M. Honarpisheh: Int. J. Adv. Manuf. Technol., 2018, vol. 95 , pp. $2757-66$.

17. L. Fratini and B. Zuccarello: Int. J. Mach. Tools Manuf., 2006, vol. 46, pp. 611-19, https://doi.org/10.1016/j.jimachtools.2005.07.013.

18. H. Jafari, H. Mansouri, and M. Honarpisheh: J. Manuf. Process., 2019, vol. 43, pp. 145-53, https://doi.org/10.1016/j.jmapro.2019.05.023.

Publisher's Note Springer Nature remains neutral with regard to jurisdictional claims in published maps and institutional affiliations. 